\title{
As relações entre o aluno com Altas Habilidades/Superdotação e 0 professor do Ensino Comum
}

\author{
The relationship between students with High \\ Ability/Giftedness and their teachers
}

Elizabeth Carvalho da Veiga ${ }^{[a]}$, Diogo Grande ${ }^{[b]}$, Simone Grochoski[ ${ }^{[b]}$

\footnotetext{
${ }^{[a]}$ Doutora em Psicologia pela Universidad Complutense de Madrid, professora titular do Curso de Psicologia da Pontifícia Universidade Católica do Paraná (PUCPR), Curitiba, PR - Brasil, e-mail: bethveiga@hotmail.com

${ }^{[b]}$ Especialistas em Educação Especial com Ênfase em Inclusão da Pontifícia Universidade Católica do Paraná (PUCPR), Curitiba, PR - Brasil, e-mails: digoometh@hotmail.com, simonegrochoski@yahoo.com.br
}

Recebido: 04/11/2011

Received: 11/04/2011

Aprovado: 16/11/2011 Approved: 11/16/2011

\section{Resumo}

O presente artigo tem como tema a relação que se estabelece entre o aluno com altas habilidades e seu professor do Ensino Comum, com o objetivo de compreender o que o aluno com altas habilidades pensa de si mesmo e como o professor qualifica e trabalha com esse aluno com características específicas. Com a finalidade de analisar esse relacionamento, foram entrevistados, a partir de questionário estruturado, quatro alunos com diagnóstico de Altas Habilidades, onze professores do Ensino Fundamental que atuam com esses alunos e os pais desses alunos. Dentre os resultados destacam-se como os alunos percebem dificuldades no relacionamento com seus professores - principalmente envolvendo falta de compreensão - e como a escola é pouco atrativa a seus interesses. Quanto aos professores, nota-se que a maioria percebe que esses alunos necessitam de atendimento diferenciado. Porém, a escola ainda não tem conseguido garantir esse atendimento.

Palavras-chave: Altas Habilidades/Superdotação. Relacionamento. Aluno. Professor.

\section{Abstract}

The main theme of this article is the relationship that exists between High Ability students and their education policy teachers to understand how the gifted students and how their teachers see them and how they work with students with specific characteristics. In order to analyze this relationship, four students diagnosed with high skills, eleven of elementary school teachers who work with these students and parents of these students were interviewed through a structured questionnaire. Among the results, we note how students perceive difficulties in relationships with their teachers - mostly involving a lack of understanding - and how the school as a whole is unattractive to their interests. For teachers, it is noted that most of them realize that these students need special attention. However, the school has not succeeded in providing this attention.

Keywords: High Ability/Giftedness. Relationship. Student. Teacher. 


\section{Introduç̃̃o}

A inclusão veio para romper com a escola tradicional nos seus modelos idealizados de aluno, de relacionamento professor/aluno/família, do que é ensino-aprendizagem, do que é avaliação, enfim, com o que é definido como "normal" e "especial". Segundo Ropoli (2010, p. 8), "a educação inclusiva concebe a escola como espaço de todos, no qual os alunos constroem o conhecimento segundo suas capacidades, expressam suas ideias livremente, participam ativamente das tarefas de ensino e se desenvolvem como cidadãos, nas suas diferenças".

Somente quando a escola reconhece as diferenças é capaz de realizar seu objetivo que é a participação e progresso de todos os seus alunos, entendendo que, para atingir seu objetivo são necessárias a busca e a adoção de novas práticas pedagógicas. Assim, uma das preocupações dos professores é fazer que o aluno se aproprie do conteúdo proposto.

Dentro do contexto escolar, o aluno superdotado deveria ser o "aluno perfeito", tanto na aprendizagem como no comportamento. Porém, essa não é a regra, e muitas das crianças superdotadas não apresentam bom rendimento escolar. São inúmeros os fatos que permeiam essas dificuldades, tendo em vista, primordialmente, a escassez de informação de como interagir e atuar biunivocamente com o aluno superdotado.

É possível que, na interação professor/aluno, existam algumas respostas para a construção de uma consciência acerca de possíveis práticas pedagógicas que existam quando o aluno apresenta altas habilidades, podendo ser positivas ou negativas, tanto do professor para com o aluno, quanto do aluno para com o professor. Diante da necessidade de o professor saber trabalhar com o aluno com altas habilidades e ter consciência de como esse aluno vê o trabalho do professor é que surge o problema desta pesquisa, tendo por objetivo compreender como é o relacionamento de ambos dentro do contexto escolar.

A literatura vigente sobre Altas Habilidades/ Superdotação é muito recente, considerando as descobertas e aprofundamento de estudos atuais. 0 modo como interagir em benefício do desenvolvimento intelectual e socialização dos jovens com essa característica ainda é uma incógnita diante da pluralidade de interações, contextos, culturas e comportamentos relacionais.

\section{Compreendendo o que são as Altas Habilidades/Superdotação}

Atualmente, a diversidade dentro da sala de aula é grande, apresentando ao professor vários desafios, como fazer que todos aprendam ou transformar sua sala de aula em um ambiente acolhedor para todos. Para que esse processo ocorra, de acordo com Stainback e Stainback (1999, p. 336), o professor deve possuir, dentre várias habilidades, conhecimento sobre a necessidade de cada aluno, estabelecendo um relacionamento positivo e trabalhando de forma a atender às necessidades de aprendizagem de todos. Ainda, é essencial o aprimoramento constante dos comportamentos, buscando superar aqueles que são inadequados.

Nesse contexto escolar, encontram-se os alunos superdotados que podem se manifestar de diversas formas: de uma "notável habilidade cognitiva e aptidão acadêmica até o comportamento criativo, habilidades de liderança e desenvolvimento artístico" (Sabatella, 2005, p. 68). Assim, pode-se considerar, em síntese, que um aluno superdotado é aquele que apresenta habilidades ou comportamentos superiores em relação à média da população, em qualquer área do saber ou do fazer.

Segundo dados da Organização Mundial da Saúde (OMS - Unesco, 2002) (Pérez, 2004; Sabatella, 2005 , p. 32), que toma como base para sua estimativa os resultados apenas nos testes do Quociente de Inteligência (QI), estima-se que 3,5\% a 5\% da população possui Altas Habilidades/Superdotação, ou seja, apresentam resultado nos testes de QI acima de 130. Quando evidenciados outros aspectos como liderança, criatividade e habilidades artísticas esse percentual sobe para $15 \%$ a $30 \%$ da população (Virgolim, 2001).

No documento A Política Nacional de Educação Especial, na perspectiva da Educação Inclusiva (Brasil, 2008b), assim como a Resolução n. 4/09 do Conselho Nacional de Educação/CNE/CEB (Brasil, 2009), no Art. 4으, § $3^{\circ}$, define como alunos que possuem Altas Habilidades/Superdotação aqueles que:

... demonstram potencial elevado em qualquer uma das seguintes áreas, isoladas ou combinadas: intelectual, acadêmica, liderança, psicomotricidade e artes, além de apresentar grande criatividade, 
envolvimento na aprendizagem e realização de tarefas em áreas de seu interesse.

Cada área apresenta características próprias que foram descritas por Virgolim (2007, p. 28):

- capacidade intelectual - rapidez de pensamento, compreensão e memória elevadas, capacidade de pensamento abstrato, curiosidade intelectual e poder excepcional de observação;

- aptidão acadêmica - atenção, concentração e motivação por disciplinas acadêmicas;

- capacidade de liderança - sensibilidade interpessoal, atitudes de cooperação, sociabilidade, capacidade para resolver situações sociais, persuasão e influência no grupo;

- capacidade psicomotora - desempenho superior em esportes e atividades físicas, agilidade e coordenação nos movimentos motores amplos e finos;

- arte - alto desempenho em artes plásticas, música, dramatizações e literatura;

- pensamento criativo - originalidade de pensamento, imaginação, resolução de problemas de forma diferenciada e inovadora.

A concepção de superdotação proposta por Renzulli et al. citado por Viera e Baptista (2009, p. 168) é baseada na existência de três traços marcantes que são: (1) habilidade acima da média, podendo ser geral, que consiste na capacidade de processar informações, integrar experiências, pensamento abstrato e habilidade específica dentro de uma atividade especializada; (2) o comprometimento com a tarefa que envolve perseverança, dedicação e o empenho pessoal; e (3) a criatividade, sendo a originalidade de pensamento, imaginação e elaboração de ideias novas predominantes.

Para Viera e Baptista (2009, p. 174), o trabalho na escola com o aluno com altas habilidades exige conhecimento, por parte do professor, do que esse aluno já domina para, assim, planejar atividades considerando tais conhecimentos. Além disso, utilizar de diferentes canais de aprendizagem, oferecer atividades complementares e estimular e respeitar a capacidade do aluno para autogerenciar sua própria aprendizagem são fundamentais. No entanto, quando as necessidades desses alunos não são atendidas, podem surgir comportamentos negativos, acarretando conflitos, e a administração nem sempre é bem-sucedida.

\section{As características da especialidade Altas Habilidades/Supertodação}

Caracterizar o aluno com Altas Habilidades/ Superdotação é um processo difícil. Em primeira instância, porque não existe um consenso entre os diversos estudiosos sobre a definição de superdotado (Alencar \& Fleith, 2001, p. 57). Outra dificuldade é o fato de este ser um grupo muito heterogêneo, pois cada indivíduo traz consigo uma combinação única de características, habilidades, interesses, estilo de aprendizagem, personalidade, que são influenciadas pelo fator genético e pela interação com o meio no qual está inserido - família, amigos e escola.

Algumas das características descritas pelos vários autores que desenvolvem pesquisas sobre Altas Habilidades/Superdotação como Alencar e Fleith (2001), Sabatella (2005), Virgolim (2007) e Winner (1998), apontam: curiosidade marcante; compreensão e retenção do conhecimento com facilidade e rapidez, sem necessidade de repetição; grande capacidade de memorização; criatividade, inventividade (pensamento flexível e original); facilidade para trabalhar em situações de independência; preocupação com questões sociais (injustiça, meio ambiente); acentuada habilidade em pensamento abstrato (raciocínio rápido, facilidade de interpretar fatos, relacionar diversas e divergentes informações); rejeição de respostas superficiais; liderança em várias áreas; grande capacidade imaginativa; raciocínio verbal e vocabulário superior à idade; nível de leitura e escrita precoces (por volta dos quatro anos de idade) acima da média do grupo; facilidade de contato social; atenção prolongada e centrada nos temas de seu interesse; fascínio por números e relações numéricas; grande bagagem de informações sobre vários temas; seus interesses podem ser amplamente diversificados ou totalmente focalizados em determinado conhecimento; sensibilidade para beleza e padrões estéticos; habilidade em artes (música, dança, desenho e pintura); habilidade para produzir respostas incomuns, únicas e inteligentes e desempenho superior em atividades físicas/esportivas.

Entre as características comportamentais do aluno com Altas Habilidades/Superdotação, Aranha 
(2005, p. 15) aponta: necessidade de envolver-se em atividades de seu interesse; interesse no convívio com pessoas de nível intelectual similar; resolução rápida de dificuldades pessoais; aborrecimento com a rotina; busca de originalidade e autenticidade; criticidade em relação a si e aos outros; alta exigência; rejeição da autoridade excessiva; fraco interesse por regulamentos e normas; senso de humor altamente desenvolvido; persistência no empenho de satisfazer suas atividades de interesse; sensibilidade às injustiças, tanto em nível pessoal quanto social; comportamento inquieto, perturbador, inoportuno; descuido na escrita; impaciência com detalhes e com a aprendizagem que requer treinamento e descuido no completar ou entregar tarefas quando desinteressado.

Cabe ressaltar que o indivíduo com Altas Habilidades/Superdotação não irá apresentar todas as características descritas, nem em simultaneidade nem em mesmo nível, assim como não irão apresentar desempenho superior em todas as situações que viverão. Muitos apresentam altas habilidades em áreas específicas de seu interesse e alguns podem ter dificuldades no processo de escolarização.

Com o conhecimento de algumas características de Altas Habilidades/Superdotação, tanto a família quanto a escola podem identificar esse sujeito e oferecer atendimento e acompanhamento adequados, bem como estimulação e compreensão para com ele, tendo em vista a prevenção de problemas de aprendizagem e socialização. Determinadas características do superdotado podem tanto facilitar quanto dificultar sua vida escolar, acarretando na geração de conflitos interpessoais e intrapessoais seja pela falta de compreensão, desconhecimento ou crenças em mitos que atrapalham a compreensão da superdotação e de suas necessidades.

Os mitos mais comuns segundo Alencar (1987), Virgolim (2003) e Winner (1998):

- o superdotado é bom em tudo - o superdotado pode apresentar elevado desempenho em algumas áreas, mas dificilmente em todas, e alguns podem até apresentar dificuldades ou atrasos em determinadas áreas;

- a criança só é superdotada porque os pais deram muitos estímulos - o papel dos pais é fundamental no suporte e encorajamento aos filhos, mas não é apenas um grande número de estímulos que leva à superdotação;
- ser superdotado é igual a ser gênio - acredita-se que o superdotado pode aprender tudo sozinho, sem auxílio ou orientação, quando, na verdade, é um aluno que necessita de apoio e atendimento dentro de suas necessidades. Além disso, o termo gênio é "reservado para descrever apenas indivíduos que já deram contribuições originais e de grande valor" (Alencar, 1987, p. 82);

- não se deve informar a criança/jovem a respeito de suas habilidades superiores - algumas pessoas acreditam que, ao saber de seu potencial elevado, o sujeito passará a agir com superioridade e arrogância, quando, ao contrário, esse aluno poderá melhor compreender-se;

- a família não deve ser informada da superdotação para que não haja cobranças e expectativas exageradas - cabe informar a família para que também compreenda as diferenças de seu filho e possa ajudá-lo com carinho, estimulo e aceitação;

- todo superdotado tem bom desempenho escolar - muitos desses alunos não vão bem no ambiente escolar. Existe uma discrepância entre seu potencial e o desempenho que realmente apresenta, assim como fatores como métodos, falta de estímulo no ambiente escolar, rejeição pelos colegas ou pressão por parte dos professores podem influenciar em seu desempenho;

- para ser superdotado tem que ter boas notas tradicionalmente foca-se apenas nos conteúdos acadêmicos e não se valorizam outras áreas como artes, música, desenho, pintura e liderança.

Todos esses mitos podem ser quebrados com a divulgação do que são as Altas Habilidades/ Superdotação. De qualquer modo, é possível observar modificações realizadas nas leis que buscam garantir ao superdotado o atendimento de suas necessidades específicas.

\section{A legislação e a pluralidade de aprendizes com Altas Habilidades/Superdotação}

O processo de aprendizagem sempre esteve, está e continuará em constante transformação. Isso se deve às modificações periódicas de contextos e à 
diversidade de maneiras de adquirir conhecimento, bem como as implicações e propósitos que as envolvem. No âmbito legal, essa obrigação é definida pela Constituição (1988) que, em seu Art. 208, estabelece o dever de assistência às pessoas com necessidades especiais:

Art. 208. 0 dever do estado com a educação será efetivado mediante a garantia de:

III - Atendimento educacional especializado aos portadores de deficiência, preferencialmente na rede regular de ensino (Brasil, 1988).

A especialidade Altas Habilidades/Superdotação não se caracteriza como uma deficiência. No entanto, encontra-se incluída na Educação Especial devido à atenção e ao trabalho criterioso e particular com as pessoas que apresentam tal especialidade.

Cronologicamente, a legislação custou a tratar as Altas Habilidades/Superdotação de forma específica, não significando descaso, mas sim fatores temporais de organização e sistematização do processo legal de intervenção. A Lei n. 4.024, de 20 de dezembro de 1961 (Brasil, 1961) dispõe sobre as diretrizes e bases da educação nacional. Para a educação especial, de forma geral, trouxe:

Art. 88. A educação de excepcionais deve no que for possível, enquadrar-se no sistema geral de educação, a fim de integrá-los na comunidade.

Art. 89. Toda iniciativa privada considerada eficiente pelos conselhos estaduais de educação, e relativa à educação de excepcionais, receberá dos poderes públicos tratamento especial mediante bolsas de estudo, empréstimos e subvenções (Brasil, 1961).

Posteriormente, a Lei n. 5.692, de 11 de agosto de 1971 (Brasil, 1971), tratando das diretrizes para o ensino de $1^{\circ}$ e $2^{\circ}$ graus, na época, evidenciou, pela primeira vez, uma particularidade sobre as Altas Habilidades/Superdotação, estruturando o marco inicial para as organizações específicas com essa especialidade:

Art. 9o Os alunos que apresentem deficiências físicas ou mentais, os que se encontrem em atraso considerável quanto à idade regular de matrícula e os superdotados deverão receber tratamento especial, de acordo com as normas fixadas pelos competentes Conselhos de Educação (Brasil, 1971).

Suas deliberações permaneceram em vigor durante 25 anos, até ser revogada pela Lei de Diretrizes e Bases da Educação Nacional n. 9.394, de 20 de dezembro de 1996 (Brasil, 1996).

Nesse período, passa-se a tratar com maior critério e destreza os encaminhamentos dados à Educação Especial. 0 Decreto n. 6.571, de 17 de setembro de 2008 (Brasil, 2008a), dispõe sobre o atendimento educacional especializado:

Art. 1ํㅡ A União prestará apoio técnico e financeiro aos sistemas públicos de ensino dos Estados, do Distrito Federal e dos Municípios, na forma deste Decreto, com a finalidade de ampliar a oferta do atendimento educacional especializado aos alunos com deficiência, transtornos globais do desenvolvimento e altas habilidades ou superdotação, matriculados na rede pública de ensino regular.

$\S 1$ o Considera-se atendimento educacional especializado o conjunto de atividades, recursos de acessibilidade e pedagógicos organizados institucionalmente, prestado de forma complementar ou suplementar à formação dos alunos no ensino regular.

$\S 2^{\circ} 0$ atendimento educacional especializado deve integrar a proposta pedagógica da escola, envolver a participação da família e ser realizado em articulação com as demais políticas públicas (Brasil, 2008a).

\section{Aspectos analíticos sobre a interação entre profissionais da educação e jovens com Altas Habilidades/Superdotação}

O aluno com Altas Habilidades/Superdotação chama atenção por suas características, sua facilidade para aprender, memorizar, defender e criar novas ideias etc. Porém, são alunos que desafiam os professores em sua rotina diária em sala de aula, o que interfere na interaçcao entre esses agentes. Assim, dificuldades nesse relacionamento são comuns e até mesmo explícitas, como também podem 
ocorrer dificuldades no relacionamento com os colegas da turma.

Das manifestações de socialização do aluno superdotado, os empecilhos que surgem no contexto escolar devem ser superados para uma relação de convivência e favorecimento do trabalho desenvolvido com essas crianças. Contudo, as práticas de interação, tanto do profissional atuante quanto do aluno que as recebe, dependendo se elas forem de acolhimento ou de repulsão, serão preponderantes para o sucesso ou não desse aluno no espaço escolar.

Não menos importante é o papel da família, que pode não estar cotidianamente na escola, mas é corresponsável pelo processo educacional, dando apoio e suporte ao filho em casa, o estimulando e o acompanhando durante a sua vida acadêmica. Ao mesmo tempo, a família tem um olhar e conhecimento de mais detalhes comportamentais, afetivos e outras características de seu filho, que muitas vezes, na escola, passam despercebidas. Essas informações que a família traz podem ser úteis para o professor entender e estabelecer vínculos e acordos com o aluno. Reciprocamente, a família também tem sua visão do filho enquanto aluno, dos relacionamentos de colegas de sala e dos professores para com seu filho.

\section{Metodologia}

A abordagem utilizada na pesquisa foi de caráter qualitativo, seguindo as características básicas definidas por Bogdan e Biklen (1982) citados por Ludke e André (1986, p. 11): "a pesquisa qualitativa tem o seu ambiente natural como fonte direta de dados e o pesquisador como seu principal instrumento". Como ambiente natural deste estudo, têm-se duas escolas comuns do Ensino Fundamental, nas quais frequentam alunos com diagnóstico de Altas Habilidades.

No processo de descrição da realidade pesquisada, consideraram-se os pontos de vista dos professores atuantes, dos alunos superdotados e de suas respectivas famílias, pois "para se realizar uma pesquisa é preciso promover o confronto entre os dados, as evidências, as informações coletadas sobre determinado assunto e o conhecimento teórico acumulado a respeito dele" (Ludke \& André, 1986, p. 1). Com a finalidade de analisar o relacionamento professor-aluno, aluno-professor e a perspectiva da família sobre esse relacionamento foi realizada, como instrumento de coleta de dados, a entrevista com questionário estruturado, sendo aplicado através de entrevista pessoal com os alunos, professores e família.

0 questionário conteve o mesmo conteúdo para as três categorias, tendo algumas adequações quando necessárias. Todos foram questionados se compreendiam o que eram as Altas Habilidades/ Superdotação e como obtiveram esse conhecimento; quais eram as principais características de superdotação e quais delas eram percebidas no sujeito com o qual tinham contato e quais características o superdotado percebia em si mesmo. Os professores foram questionados se houve a necessidade de modificações na metodologia de trabalho com o aluno com altas habilidades, se recebeu e de quem recebeu orientações de como trabalhar com o aluno superdotado e como era o seu relacionamento com esse aluno e da turma para com ele. Para os alunos, foi solicitada uma avaliação do trabalho do professor em sala de aula sobre como percebiam seu relacionamento com os professores e colegas de classe. A família respondeu sobre ter notado algum trabalho diferenciado do professor devido às características do seu filho e se estava preparado para esse trabalho, bem como perceber o relacionamento do professor e colegas da turma para com seu filho. Foram utilizadas duas questões abertas onde os entrevistados expressaram sua opinião sobre quais eram as principais dificuldades envolvendo o trabalho com altas habilidades e quais as formas ou meios para tentar sanar essas dificuldades.

Um dos estudantes entrevistados é do $2^{\circ}$ ano do Ensino Fundamental na rede municipal de ensino de São José dos Pinhais (PR), que possui diagnóstico de elevado desempenho na linguagem oral, leitura, memória e na área lógico-matemática. Porém, o aluno ainda encontra-se em acompanhamento para descobrir suas áreas de interesse, com 6 anos de idade.

Os outros três estudantes entrevistados, juntamente com seus familiares, cursam o Ensino Fundamental na rede municipal de ensino de Curitiba (PR). Todos se encontram nos ciclos finais de ensino, numa escola da rede que oferece ensino de $1^{\circ}$ ao $9^{\circ}$ ano. A mais jovem, com 12 anos de idade, cursa o $7^{\circ}$ ano, possuindo destaque na área artística e linguístico-verbal, estuda na escola desde o 
$1^{\circ}$ ano. 0 segundo é um adolescente com 12 anos de idade e estuda na escola desde o $1^{\circ}$ ano. Conforme diagnóstico possui ênfase nas áreas lógico-matemática e visuoespacial; cursa o $8^{\circ}$ ano. 0 terceiro jovem tem 14 anos de idade e cursa o 9o ano do Ensino Fundamental. Estuda na escola desde o 7음 ano, sendo retido por dois anos consecutivos num outro estabelecimento de ensino. Nessa etapa do ciclo III, antes de ser matriculado nessa escola, no ano anterior, após diversos procedimentos, sofreu processo de aceleração. Esse aluno apresenta, conforme diagnóstico, desenvolvimento superior nas áreas cinestésico-corporal e visual.

Participaram da pesquisa três professores que atuam no Ensino Comum com o aluno do município de São José dos Pinhais (PR) e oito professores que atuam com os três alunos do município de Curitiba (PR), que lecionam em diversas áreas do conhecimento.

\section{Análise dos resultados}

A amostra de entrevistados desta pesquisa não representa uma população segundo critérios estatísticos por ser pequeno o número de entrevistados. Ainda assim, corrobora com os estudos realizados nessa área. Apesar de um dos alunos com diagnóstico ter idade de 6 anos, não se evidenciou diferenças qualitativas nas suas repostas se comparadas com as dos adolescentes de 12-14 anos de idade.

0 primeiro questionamento da entrevista com alunos, professores e pais foi sobre o conhecimento do que são as Altas Habilidades/Superdotação. A grande maioria dos sujeitos entrevistados tinha conhecimento sobre o conceito de superdotação. Uma pequena amostra dos professores considerou que apenas ouviu falar sobre esse tema. Entre os alunos com diagnóstico, metade apresentou conhecimento sobre a especialidade e a outra metade como só tendo ouvido falar sobre o assunto.

Como a maioria dos entrevistados considerou ter conhecimento sobre as Altas Habilidades/ Superdotação, questionou-se de que forma ou fonte esses indivíduos obtiveram esse conhecimento. Destaca-se que $21 \%$ dos entrevistados afirmam ter buscado informações por curiosidade pessoal e $20 \%$ obtiveram informações através de cursos e palestras de capacitação ou extensão. Dezesseis por cento assimilaram informações em seus respectivos cursos de graduação e especialização, assim como a mesma porcentagem só conheceu as Altas Habilidades quando teve contato com um aluno com diagnóstico. Como Virgolim (2007, p. 10-11) explica, "o tema das altas habilidades/ superdotação é ainda pouco discutido em nossas universidades, o que produz uma lacuna na formação dos professores. Muitos saem de seus cursos sem terem a oportunidade de conhecer esta área tão importante do desenvolvimento da criança".

Setenta e cinco por cento dos respondentes do grupo família tinham conhecimento sobre o que era superdotação a partir do processo de investigação do filho que gerou um laudo com o diagnóstico. 0 restante foi por curiosidade pessoal, em decorrência das características do filho que chamavam a atenção antes da avaliação. Quanto ao grupo dos alunos, $75 \%$ somente obtiveram conhecimento sobre as altas habilidades quando passaram a frequentar os atendimentos especializados e $25 \%$ afirmaram não ter conhecimento sobre o que realmente é o termo que os qualifica.

Apenas conhecer o significado do que é uma alta habilidade não é suficiente. É necessário que professores e pais percebam e identifiquem as características que compõem um quadro de superdotação. Com as informações adequadas, os professores e pais têm papel fundamental para a identificação desses sujeitos e quanto antes o diagnóstico for realizado, mais cedo será possível atender a suas necessidades.

Dos 11 professores entrevistados, no questionamento sobre conhecer/identificar as características da superdotação., oito identificam somente algumas características, dois reconhecem todas as características e um professor afirma que não conhece. As famílias são as que menos percebem essas características. Virgolim (2007, p. 10-11) afirma que, para "os pais, o desconhecimento é ainda maior, uma vez que nossa sociedade ainda trata esse tema como tabu", e segundo Aspesi (2007, p. 41), "carregando esse tema de mitos e estereótipos, gerando preconceitos que confundem os pais no processo de compreensão das características dos filhos". Quanto aos alunos, metade percebe características que os diferenciam dos outros alunos e a outra metade não percebe nenhuma característica marcante para diferenciá-los.

Como todos os alunos que participaram da pesquisa já possuem o diagnóstico de Altas Habilidades / Superdotação e já frequentam escolas em que estão matriculados há mais de um ano, parte considerável 
dos profissionais da educação e equipe pedagógica da escola conhece o diagnóstico e convive com o aluno. Isso permite ao professor perceber se existe a necessidade de adaptações ou modificações em atividades que serão desenvolvidas no grupo em que está inserido. Pelas considerações dos profissionais, $46 \%$ adaptaram algumas atividades conforme o andamento e a aquisição da aprendizagem do aluno e $23 \%$ afirmaram não ver a necessidade de nenhuma modificação para atender o aluno com Altas Habilidades/Superdotação. Percebe-se que os professores já notaram a necessidade de, pelo menos em alguns momentos, adequar atividades para atender esse aluno. Segundo Novaes (1979, p. 55), "em um planejamento educacional realista, o ponto nuclear seria não exigir demais desse aluno, mas estimulá-lo diferentemente, adequando estratégias de ensino, metodologias e oferecendo currículos enriquecidos".

A literatura aponta a necessidade de identificação do indivíduo com Altas Habilidades/ Superdotação o mais cedo possível para dar os estímulos adequados e evitar possíveis problemas como desinteresse. No entanto, "essa identificação só terá sentido se for possível oferecer, também, um conjunto de práticas educativas que venham atender às necessidades e favorecer o desenvolvimento do aluno" (Guimarães \& Ourofino, 2007, p. 55). É preocupante notar que, na amostra pesquisada, $33 \%$ dos profissionais da educação alegam não ter recebido nenhuma orientação para trabalhar com o aluno com Altas Habilidades/Superdotação que está inserido em sua sala de aula e que $25 \%$ tiveram de buscar orientações por iniciativa própria. Com isso, ficam evidenciadas a pouca participação e intervenção da equipe pedagógica da escola e a mínima atuação da equipe multidisciplinar no sentido de orientar o professor na busca de novas práticas pedagógicas e na elaboração de atividades que possam estimular o aluno com altas habilidades.

Considerando esses dados, é duvidoso e arriscado o método pelo qual o professor afirma utilizar adaptações de algumas atividades para trabalhar com as Altas Habilidades/Superdotação. Com isso, evidencia-se a falta de critérios e a confirmação do procedimento adequado torna-se ainda mais remota. Ainda, somente com essas modificações, é questionável se seu nível de conhecimento sobre essa área é adequado, uma vez que não tem o apoio de outros profissionais mais capacitados no processo de aprendizagem em questão.
Solicitou-se aos alunos a avaliação do trabalho do professor em sala de aula, isto é, de como, particularmente, eles observam tal atuação. 0 trabalho do professor é caracterizado entre positivo e intermediário. Apesar de a avaliação do trabalho do professor na perspectiva de garantir a aprendizagem de todos os alunos ser considerada boa, quando se questionou sobre o relacionamento do professor com o aluno superdotado, percebeu-se que esse convívio não é positivo - 50\% dos alunos entrevistados julgaram regular ou ruim.

Os problemas de relacionamento não estão centrados apenas nos professores. Os alunos com altas habilidades também apontam dificuldades com outras pessoas, principalmente com os colegas de classe.

As características das Altas Habilidades/ Superdotação podem se manifestar de forma construtiva, favorecendo a aprendizagem e boas relações interpessoais, como podem se manifestar de forma conturbada, determinando relações interpessoais difíceis e dolorosas. Nesse caso, pode ocorrer intolerância, ridicularização e falta de compreensão por parte dos colegas, bem como o aluno ser considerado estranho pelos professores. Assim, algumas das características desse aluno podem ser entendidas como problema. Aranha (2002, p. 18-20) aponta que o aluno com altas habilidades pode falar em demasia em sala de aula sobre assuntos que os seus colegas não acompanham ou não têm interesse; ter resistência em parar de falar do assunto de que gosta; por aprender rápido, ser negligente com os conteúdos acadêmicos; ter resistência a cumprir regras; não aceitar ajuda; ser muito perfeccionista consigo e com os outros; discordar verbalmente de seus professores e não querer seguir as rotinas estabelecidas pela escola.

É necessário que a escola busque formas de integração e ajuda para o aluno com Altas Habilidades / Superdotação. Isso propicia ao aluno utilizar suas habilidades e competências em benefício próprio, tanto na aprendizagem como em sua afetividade e socialização, para que possa se sentir confiante, participativo e aceito por colegas e professores. Para superar o que Pati (1988, p. 75-76) verificou em sua pesquisa, onde os superdotados que ela entrevistou apontaram o ambiente escolar com o maior número de relatos de insatisfação, desânimo, rebeldia, rejeição e sofrimento, as maiores fontes de problemas foram as atitudes de professores e colegas diante de sua maneira diferente de ser. 
Pode-se perceber ainda que variados fatores predominantes no ambiente escolar interferem diretamente no grau de relacionamento dos alunos com altas habilidades. No entanto, os pontos de visão sobre essas relações são diferenciados.

Destacando-se os fatores apontados pelos pais dos alunos em questão, tornou-se evidente que as dificuldades de relacionamento, em suma, se concentram na dinâmica de ações e trabalho com o profissional da educação regente. Em contrapartida, os professores apontaram que os focos problemáticos vividos se dão em suas próprias relações com os alunos e do aluno com a classe, não observadas dificuldades somente com o andamento de seu respectivo trabalho. Em relação aos estudantes, em contribuição às informações fornecidas, cada aluno mostrou preocupações em relacionar-se tomando como fator preponderante suas maiores dificuldades, sejam com professores, equipe pedagógica da escola ou até mesmo a socialização na escola. Há destaque para um dos alunos, que afirmou que não observa problemas de relacionamento com ninguém que se relaciona na escola.

As evidências tornam-se ainda mais concretas quando se observa a pluralidade de caminhos seguidos pelos professores na aquisição de informações e métodos para atuar com êxito na educação dos alunos superdotados. Observou-se com caráter preocupante e até emergencial a falta de diretrizes e suporte no tratamento de sucesso à educação inclusiva e de direito de todos. As intervenções da equipe pedagógica escolar existem e são necessárias, no entanto, são insuficientes diante do contexto de uma educação que se almeja e de uma educação da forma como se apresenta hoje.

Tendo em vista as políticas educacionais, a orientação e o embasamento para o desenvolvimento de um trabalho de qualidade pela mantenedora responsável ficaram praticamente sem consideração devido ao percentual mínimo referente à atuação de equipes multidisciplinares junto ao progresso educacional e relacional do aluno superdotado. Contudo, as opções de alternativas múltiplas de métodos de auxílio educacionais são alarmantes com 25\% dos profissionais buscando orientações por iniciativa própria e 33\% sem orientações sobre como interagir, atuar e desenvolver propostas sólidas de trabalho.

0 valor da relação desenvolvida com os alunos superdotados, apesar das dificuldades organizacionais existentes, é notável no sucesso obtido por mais da metade dos professores na atuação com os estudantes com altas habilidades. Conforme seus pareceres, as classificações ótimo e bom tem considerável destaque, mostrando a tomada de iniciativa e atuação consistente dos profissionais na busca de soluções e possíveis amenizações de conflitos em classe. Cabe evidenciar com caráter de extrema preocupação que o mesmo não é demonstrado e sensibilizado pelos alunos, classificando de forma negativa essa relação.

Contudo, o trabalho desenvolvido pelo professor e a forma de ministrar suas aulas são consideravelmente reconhecidos pelos alunos superdotados. 0 nível de percepção e visualização da realidade vivenciada pelos estudantes em questão é criterioso e minucioso, mostrando-se muito claros no que concordam ou não, no que aceitam ou não e em como se posicionam diante dos variados acontecimentos $\mathrm{e}$ contextos escolares. Durante as entrevistas, afirmações como "se alguém começa a falar comigo a culpa é minha"; "eu pergunto, mas o professor não ouve"; "ninguém gosta de mim"; "sou mau aluno"; refletem as possíveis sensações de insatisfação e princípios de revolta dos alunos em meio às intervenções muitas vezes impostas. Porém, a sensatez é dominante na valorização dos propósitos estabelecidos pelos professores para consigo e sua classe.

A maioria dos professores entrevistados julgou regular a realização do trabalho com o estudante com altas habilidades. Os extremos não foram citados. Porém, os patamares regular e intermediário em ambos os pontos de visão foram altamente selecionados, considerando-se os pareceres nos diferenciados contextos de vivência.

Contudo, diante dos procedimentos conturbados de orientação e acompanhamento do trabalho com os superdotados, a falta de suporte na atuação em classe comum e os imprevistos relacionais e conflituosos que o profissional da educação deve sanar na dinâmica escolar cotidiana, várias dificuldades e também formas de minimizar o problema foram levantadas pelos professores.

A pesquisa mostra que se obtém o que deve ser o mínimo de recurso oferecido e, em suma, a base não suficiente, mas necessária no enriquecimento do atendimento global à educação dos superdotados. Tem-se enorme importância, a preocupação de quais meios devem ser utilizados para que os $37 \%$ referentes à dificuldade do envolvimento com a tarefa sejam reduzidos. Com isso, propõe-se uma solução, 
acompanhada de uma proposta metodológica consistente, em relação às atividades atrativas e desafiadoras, totalizando $46 \%$ dos apontamentos listados.

Entretanto, uma das maiores evidências contraditórias da pesquisa realizada aqui se sustenta. Somente $8 \%$ dos profissionais destacam enorme mudança em sua metodologia de trabalho com a classe do estudante com altas habilidades; $23 \%$ afirmaram alterações metodológicas significativas somente para o aluno superdotado. Isso significa que $69 \%$ dos professores não realizam qualquer alteração em sua prática docente ou, se realizam, promovem tal alteração em propostas isoladas, uma vez que os mesmos profissionais sugerem atividades atrativas e desafiadoras num percentual de $46 \%$.

Na visão dos pais dos estudantes superdotados, o envolvimento com a tarefa possui considerável evidência, somado à falta de interesse em conhecer as características da especialidade superdotação e, até mesmo, da aceitação do incomum. Ainda, a incapacidade de despertar o interesse do aluno e a promoção valorosa e provocativa dos assuntos tratados em classe é precária quanto à garantia de participação colaborativa e geral do superdotado. Os familiares são unânimes em afirmar a necessidade da aceitação e capacitação eficiente para o progresso no tratamento educacional oferecido ao estudante com altas habilidades.

\section{Considerações finais}

No movimento atual da Educação Inclusiva, torna-se essencial compreender que cada aluno tem o direito a frequentar a escola e esta lhe garantir o acesso ao aprendizado, aceitando seu ritmo e nível de aprendizagem, com programas adequados e atitudes positivas. Como Stainback e Stainback (1999, p. 69) alertam, "as boas escolas são boas escolas para todos os alunos", independentemente se são alunos com deficiências ou superdotados. Para que isso aconteça é necessária a reorganização do trabalho pedagógico tendo como princípio a diversidade. Pacheco (2010, p. 10) destaca que é importante educar, o que é mais amplo que escolarizar; o autor acrescenta que a heterogeneidade é fator para aprendizagem, cada aluno é único e todas as crianças são diferentes, logo todas são especiais.

No caso dos alunos com Altas Habilidades/ Superdotação é necessário que a escola abra espaço para que esses alunos desenvolvam suas habilidades, dando condições para que eles se sintam confiantes, participativos. Virgolim (2007, p. 9) esclarece que é vital para a criança sentir que é aceita pelos professores e colegas de classe. A não validação e contemplação das habilidades avançadas no currículo, atividades rígidas, pouco criativas, centradas na repetição de conteúdo, aulas monótonas e pouco estimuladoras e o ritmo mais lento da classe, podem gerar no superdotado a atitude de resistência, tanto passiva - falta de atenção, desinteresse - como ativa - destrutividade, combatividade - perante professores e colegas. Para atingir esse tipo de aluno pela prática pedagógica, necessita-se evoluir para a pesquisa, criatividade, observação e análise (Duarte, 1988. p. 114). Para o professor, vem o desafio de manter a motivação do aluno e, ao mesmo tempo, mostrar que a escola é um espaço que tem regras, ritmo próprio, organização e todos os alunos devem se submeter a essas características.

Cabe lembrar que o superdotado tem as mesmas necessidades de aceitação, compreensão e orientação que qualquer criança, apresentando momentos de dúvidas e insegurança. Porém, como superdotado, apresentará facilidades e habilidades acima da média de seu grupo, as quais deverá aprender a usar de forma eficiente e construtiva. É fundamental e essencial o papel dos pais e professores em orientar, motivar, disciplinar, dar acesso a novos conhecimentos e desenvolver bons hábitos de estudos.

Os pais, entre outras funções, precisam oferecer ao filho "proteção, apoio, disponibilidade de afeto, mas também presença real, de forma que esta criança/adolescente possa encontrar adequadas referências e possa sentir segurança em dividir suas ansiedades e interesses com seus pais" (Costa, 2000, p. 174).

Segundo Novaes (1979 p. 132-133), para estabelecer um bom vínculo com o aluno com Altas Habilidades/Superdotação cabe ao professor em sala de aula: aceitar o aluno como ele é; assumir seus próprios limites enquanto professor; ser disponível e sensível às solicitações dos alunos; ser firme em suas proposições; não competir nem medir forças com o superdotado; estabelecer relação de ajuda e apoio; não exigir nem esperar muito do aluno superdotado; não o expor aos colegas nem o superproteger; não projetar no aluno seus desejos e aspirações.

O aluno com Altas Habilidades/Superdotação têm necessidades educacionais especiais; por esse 
motivo, o professor deve ajudá-lo a reduzir a discrepância entre suas habilidades e seu rendimento acadêmico (quando houver), trabalhar as habilidades sociais e, junto com os pais, procurar formas de melhor atender esse aluno.

Tanto o professor quanto o aluno devem aprender a conviver, lidar com suas emoções e sentimentos. Para que ambos possam estabelecer relações autênticas, positivas e equilibradas. Segundo Novaes (1976, p. 53), um dos pontos de conflito desse relacionamento reside no fato de que "é sempre mais exigido do aluno que se adapte às condições impostas pela escola e pelos professores; poucas vezes, indagamos se a própria escola e os professores estão se adaptando aos alunos, às suas necessidades, interesses e características pessoais".

A escola deve sempre respeitar a criança, permitir que ela se mostre dentro de suas possibilidades, estimular sua autoconfiança e manter a curiosidade e imaginação presentes nas atividades de sala de aula. Para atingir tal objetivo, é necessário que o ensino seja: ativo - estimular a participação, evitar a repetição e monotonia, utilizar técnicas e recursos variados, favorecer o uso da experiência; progressivo - dosar adequadamente os conteúdos, respeitar o desenvolvimento de todos os alunos; individualizado - procurar conhecer cada aluno, levar em conta os interesses e aptidões de cada um, considerar o ritmo de aprendizagem e atender às diferenças individuais (Novaes, 1986, p. 21).

Quando o foco de estudo são as relações humanas de forma global, os parâmetros de estudo e análises detêm a influência de inúmeros contextos. Quando se restringe a um grupo de estudo, em especial os estudantes de Ensino Comum que têm Altas Habilidades/Superdotação, o emaranhado de contextos se mantém, trazendo ainda mais ramificações ocasionadas pelas novidades e abordagens de um estudo recente.

Uma dessas ramificações diz respeito a como se dá a relação professor-aluno e aluno-professor no ensino comum, tendo o aluno Altas Habilidades/ Superdotação. Conforme o estudo e análise realizadas, admite-se ser uma relação que necessita de aprimoramento, tendo em vista as interações conturbadas, conflituosas e que, em muitas vezes, não acarretaram objetivos satisfatórios a ambas as vertentes de pesquisa.

Especificamente na relação do professor para seu aluno superdotado, é evidente o caráter da preocupação e da necessidade de tomada de medidas, providências, acompanhamento dos processos metodológicos e subsídios que sustentem uma interação de aprendizagem e crescimento intelectual de bases e progresso comum. A busca de conhecimento por iniciativa própria obteve resultado satisfatório, tendo em vista que o despreparo e o número reduzido de condições favoráveis de interação e trabalho são alarmantes.

Quanto à relação do aluno para seu professor regente - professores no caso dos anos finais do Ensino Fundamental nas diversas áreas do conhecimento as enunciações apresentaram certa relatividade conforme o professor de que se estava tratando, tendo em vista a pluralidade de visões, métodos de trabalho e o nível crítico cada vez mais intenso dos adolescentes superdotados. A sensatez e a manifestação justa e criteriosa sobre cada questionamento relacional e de desempenho imperaram na análise dos resultados. As condições favoráveis e desfavoráveis, segundo seus pontos de vista, foram explicitadas com o intuito de reflexão e propostas de melhora e progressão no nível relacional e ações globais escolares.

\section{Referências}

Alencar, E. S. (1987, out.). Crenças e idéias errôneas sobre o superdotado. Anais do V seminário Nacional sobre Superdotados. Rio de Janeiro, RJ.

Alencar, E. S., \& Fleith, D. S. (2001). Superdotados: Determinantes, educação e ajustamento (2a ed.). São Paulo: EPU.

Aranha, M. S. F. (2005). Desenvolvendo competências para o atendimento às necessidades educacionais de alunos com altas habilidades/superdotação. Brasília: Ministério da Educação, Secretaria de Educação Especial.

Aranha, M. S. F. (2002). Projeto escola viva: Garantindo o acesso e permanência de todos os alunos na escola - alunos com necessidades educacionais especiais. Brasília: Ministério da Educação, Secretaria de Educação Especial.

Aspesi, C. C. (2007). A família do aluno com altas habilidades/superdotação. In D. Souza (Org.), A construção de práticas educacionais para alunos com altas habilidades/superdotação. Brasília: Ministério da Educação, Secretaria de Educação Especial. PMCid:1785147. 
Brasil (1961). Lei n. 4.024, de 20 de dezembro de 1961. Brasília. Recuperado em 14 jul. 2011, de http:// www.histedbr.fae.unicamp.br/navegando/fontes_escritas/6_Nacional_Desenvolvimento/ldb\%20lei\%20 no\%204.024,\%20 de \%2 020\%20 de\%20 dezembro\%20de\%201961.htm.

Brasil (1971). Lei n. 5.692, de 11 de agosto de 1971. Brasília. Recuperado em 14 jul. 2011, de http:// www.planalto.gov.br/ccivil_03/leis/15692.htm.

Brasil (1988). Constituição da República Federativa do Brasil de 1988. Brasília. Recuperado em 14 jul. 2011, de http://www.planalto.gov.br/ccivil.

Brasil (1996). Lei n. 9.394, de 20 de dezembro de 1996. Brasília. Recuperado em 15 jul. 2011, de www.mec. gov.br/seesp.

Brasil (2008a). Decreto n. 6.571, de 17 de setembro de 2008. Dispõe sobre o atendimento educacional especializado. Brasília. Recuperado em 15 ago. 2011, de http://www.planalto.gov.br/ccivil_03/_ Ato20072010/2008/Decreto/D6571.htm.

Brasil (2008b). Política nacional de educação especial na perspectiva da educação inclusiva, de outubro de 2008. Brasília. Recuperado em 15 jul. 2011, de www. mec.gov.br/seesp.

Brasil (2009). Resolução n. 4, de 2 de outubro de 2009. Brasília. Recuperado em 15 jul. 2011, de www.mec.gov.br.

Costa, M. R. N. (2000). Um estudo sobre o adolescente portador de altas habilidades: seu "olhar" sobre si mesmo. Seu "olhar" sobre o "olhar" do outro. Dissertação de Mestrado, Universidade Federal do Rio Grande do Sul, Porto Alegre, RS.

Duarte, R. M. P. (1988, out.). Psicomotricidade e superdotação. Anais do VII seminário nacional sobre superdotados. Rio de Janeiro, RJ.

Guimarães, T. G., \& Ourofino, V. T. (2007). Estratégias de identificação do aluno com altas habilidades/ superdotação. In D. S. Fleith (Org.), A construção de práticas educacionais para o aluno com altas habilidades superdotação. Brasília: Ministério da Educação, Secretaria de Educação Especial.

Lucke, M., \& André, M. E. D. A. (1986). Pesquisa em educação: Abordagens qualitativas. São Paulo: EPU.

Novaes, M. H. (1976). Adaptação escolar: Diagnóstico e orientação. Petrópolis, RJ: Vozes.
Novaes, M. H. (1979). Desenvolvimento psicológico do superdotado. São Paulo: Atlas.

Novaes, M. H. (1986). Psicologia do ensino-aprendizagem. São Paulo: Atlas.

Pacheco, J. (2010). Ter laudo, ou não ter laudo... eis a questão? In I. Parolin (Org.). Nossas crianças não podem mais esperar? A inclusão escolar em foco. São José dos Campos: Pulso Editorial.

Pati, V. (1988, out.). Auto-percepção do superdotado: Resultado de pesquisa. Anais do VII seminário nacional sobre superdotados. Rio de Janeiro, RJ.

Pérez, S. G. P. B. (2004). 0 aluno com altas habilidades/superdotação: Uma criança que não é o que deve ser ou é o que não deve ser? In C. D. Stobaus \& J. J. Mosquera (Org.). Educação especial: Em direção à educação inclusiva. Porto Alegre: Ed. da PUCRS.

Ropoli, E. A. (2010). A educação especial na perspectiva da inclusão escolar: A escola comum inclusiva. Brasília: Ministério da Educação, Secretaria de Educação Especial.

Sabatella, M. L. P. (2005). Talento e superdotação: Problema ou solução? Curitiba: Ibpex.

Stainback, S., \& Stainback, W. (1999). Inclusão: Um guia para educadores. Porto Alegre: Artmed. PMCid:325597.

Viera, N. J. W., \& Baptista, C. R. (2009). Educação e altas habilidades: incluir... sim, mas como?. In C. R. Baptista (Org.). Inclusão e escolarização: Múltiplas perspectivas. Porto Alegre: Mediação.

Virgolim, A. M. R. (2001). A criança superdotada em nosso meio: aceitando suas diferenças e estimulando seu potencial. Escola de Pais do Brasil. Secção de Brasília.

Virgolim, A. M. R. (2003). A criança superdotada e a questão da diferença: Um olhar sobre suas necessidades emocionais, sociais e cognitivas. Brasília: Linhas Críticas.

Virgolim, A. M. R. (2007). Altas habilidades/superdotação: Encorajando pontenciais. Brasília: Ministério da Educação, Secretaria de Educação Especial.

Winner, E. (1998). Crianças superdotadas: Mitos e realidades. Porto Alegre: Artmed. 